\title{
A p38 Mitogen-Activated Protein Kinase-Dependent Mechanism of Disinhibition in Spinal Synaptic Transmission Induced by Tumor Necrosis Factor- $\alpha$
}

\author{
Haijun Zhang, Hui Nei, and Patrick M. Dougherty \\ Department of Pain Medicine, The University of Texas MD Anderson Cancer Center, Houston, Texas 77030
}

\begin{abstract}
Tumor necrosis factor- $\alpha(\mathrm{TNF} \alpha)$ is a proinflammatory cytokine that contributes to inflammatory and neuropathic pain. The mechanism by which TNF $\alpha$ modulates synaptic transmission in mouse substantia gelatinosa was studied using whole-cell patch clamp and immunohistochemistry. TNF $\alpha$ was confirmed to significantly increase the frequency of spontaneous EPSCs (sEPSCs) in spinal neurons and to also produce a robust decrease in the frequency of spontaneous IPSCs (sIPSCs). The enhancement of excitatory synaptic transmission by TNF $\alpha$ is in fact observed to be dependent on the suppression of sIPSCs, or disinhibition, in that blockade of inhibitory synaptic transmission prevents the effect of TNF $\alpha$ on sEPSCs but not vice versa. TNF $\alpha$-induced inhibition of sIPSCs was blocked by neutralizing antibodies to TNF receptor 1 (TNFR1) but not to TNFR2 and was abolished by the p38 mitogen-activated protein kinase inhibitor SB202190 [4-(4-fluorophenyl)-2-(4-hydroxyphenyl)-5-(4-pyridyl) $1 H$-imidazole]. TNF $\alpha$ rapidly inhibited spontaneous action potentials in GABAergic neurons identified in transgenic mice expressing enhanced green fluorescent protein controlled by the GAD67 promoter. This inhibitory effect was also blocked by intracellular delivery of SB202190 to the targeted cells. The inhibition of spontaneous activity in GABAergic neurons by TNF $\alpha$ is shown as mediated by a reduction in the hyperpolarization-activated cation current $\left(I_{\mathrm{h}}\right)$. These results suggest a novel TNF $\alpha$-TNFR1-p38 pathway in spinal GABAergic neurons that may contribute to the development of neuropathic and inflammatory pain by TNF $\alpha$.
\end{abstract}

\section{Introduction}

Tumor necrosis factor- $\alpha$ (TNF $\alpha)$, one of the major proinflammatory cytokines released in response to injury or inflammation, plays an essential role in the development of inflammatory (Cunha et al., 1992; Ferreira et al., 1993; Watkins et al., 1995; Woolf et al., 1997) and neuropathic pain (Sommer et al., 1998a,b, 2001a,b; Lindenlaub et al., 2000; Sorkin and Doom, 2000; Schäfers et al., 2003a). The effects of TNF $\alpha$ not only include transcriptional regulation of downstream inflammatory mediators but also include a rapid sensitizing effect on targeted cells. For example, TNF $\alpha$ lowers threshold in A $\beta$ - and C-fibers (Junger and Sorkin, 2000; Liu et al., 2002; Zhang et al., 2002; Schäfers et al., 2003b) and enhances transient receptor potential vanilloid receptor 1 (TRPV1) (Nicol et al., 1997) and TTXresistant sodium currents in primary sensory neurons (Jin and Gereau, 2006). Compared to its peripheral effects, the central effects of TNF $\alpha$ are much less well understood. Intrathecal injection of TNF $\alpha$ induces mechanical allodynia and heat hyperalgesia

Received May 12, 2010; revised June 29, 2010; accepted Aug. 5, 2010.

This work was supported by National Institutes of Health Grant NS46606 and National Cancer Institute Grant CA124787. We thank DNA Analysis Core Facility in MD Anderson Cancer Center for the assistance with mouse colony genotyping and X. Ao for the assistance with confocal microscopy. We also thank Dr. Bharat Aggarwal for the donation of TNF R1 and R2 antibodies.

Correspondence should be addressed to Patrick M. Dougherty, Department of Pain Medicine, The University of Texas MD Anderson Cancer Center, 1400 Holcombe Boulevard, Unit 409, Houston, TX 77030. E-mail: pdougherty@ mdanderso.org.

DOI:10.1523/JNEUROSCI.2437-10.2010

Copyright $\odot 2010$ the authors $\quad 0270-6474 / 10 / 3012844-12 \$ 15.00 / 0$
(Narita et al., 2008; Gao et al., 2009). TNF upregulates excitatory synaptic spinal transmission and cAMP response elementbinding protein (CREB), a pronociceptive gene, in spinal cord dorsal horn (Kawasaki et al., 2008) and recruits $\mathrm{Ca}^{2+}$ permeable AMPA receptors in dorsal horn neurons in carrageenan-induced inflammation (Choi et al., 2010).

p38 mitogen-activated protein kinase (MAPK) is a stressactivated protein kinase with a major role in the development of inflammatory and neuropathic pain (for review, see Ji et al., 2009). Activation of $\mathrm{p} 38$ is common in dorsal root ganglion (DRG) and spinal cord in various pain models (Ji et al., 2002; Jin et al., 2003; Zhuang et al., 2007). The activation of p38 in DRG neurons results in increased expression of TRPV1 (Ji et al., 2002) and enhancement of TTX-resistant sodium currents, suggesting a shared effect with TNF $\alpha$ (Jin and Gereau, 2006). In addition, intrathecal application of specific p38 antagonists prevents the development of hyperalgesia and allodynia in inflammatory and neuropathic pain models (Jin et al., 2003; Schäfers et al., 2003a; Svensson et al., 2003; Boyle et al., 2006; Sorkin et al., 2009). The effects of p38 activation in spinal cord remains to be more fully explored, yet there are data to support a role of p38 in spinal synaptic plasticity during central sensitization (Garry et al., 2005).

Because the spinal substantia gelatinosa (SG) is a critical site in nociceptive transmission (Willis and Coggeshall, 2004) and altered functions of SG neurons are implicated in the development and maintenance of inflammatory and neuropathic pain (Castro-Lopes et al., 1993; Ibuki et al., 1997; Eaton 
A

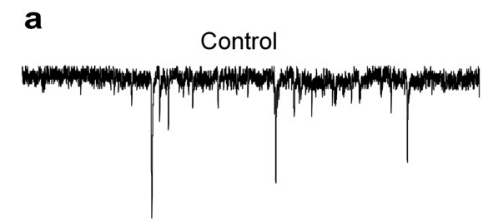

b

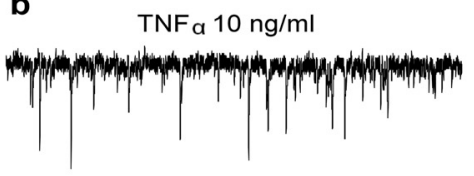

C

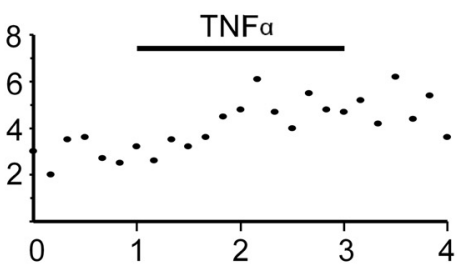

B

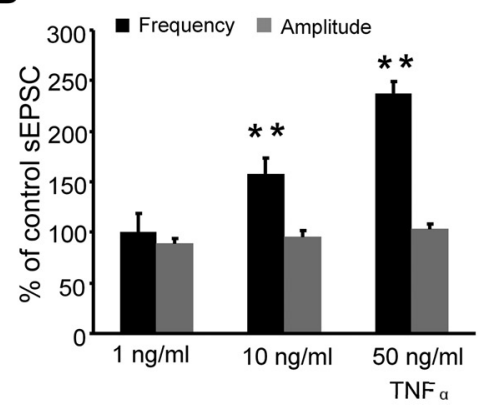

C

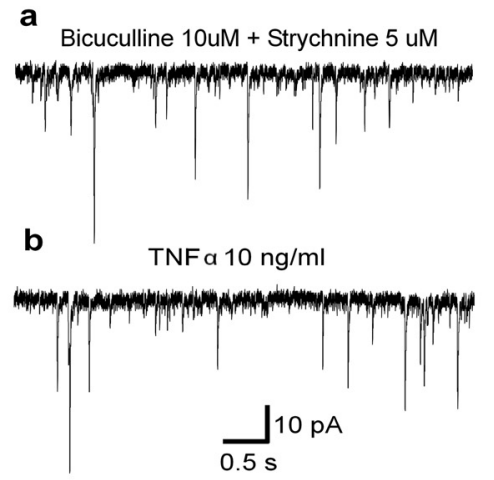

C

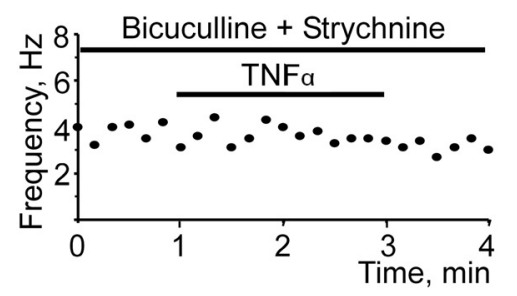

D

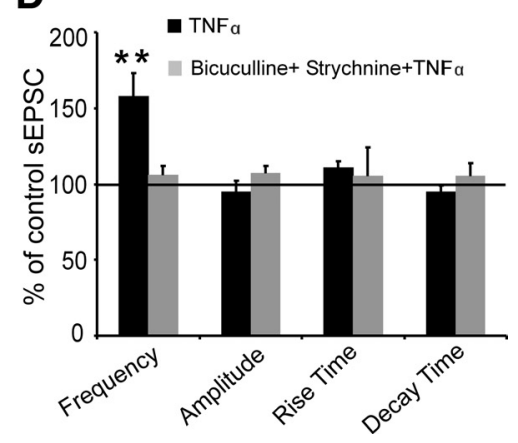

Figure 1. TNF $\alpha(10 \mathrm{ng} / \mathrm{ml}, 2 \mathrm{~min})$ enhances excitatory synaptic transmission in spinal dorsal horn. $\boldsymbol{A}$, sEPSCs recorded from a spinal lamina II neuron before $(\boldsymbol{a})$ and after $(\boldsymbol{b})$ the application of TNF $\alpha ; \boldsymbol{A c}$, frequency of sEPSCs as a function of recording time in the representative cell in $\boldsymbol{A} \boldsymbol{a}$ and $\boldsymbol{A b}$. Frequency was measured every 10 s. $\boldsymbol{B}$, TNF $\alpha$ enhances sEPSC in a concentration-dependent manner. The significant effect on sEPSCs was observed at $10(n=11)$ and $50(n=4)$ but not $1(n=5) \mathrm{ng} / \mathrm{ml} \mathrm{TNF} \alpha .{ }^{* *} p<0.01$ (one-way ANOVA with post hoc Dunn's test). C, In the presence of bicuculline (10 $\mu \mathrm{m})$ plus strychnine (10 $\mu \mathrm{m})$ in the bath, application of TNF $\alpha$ had no effect on SEPSCS. D, Grouped data showed the percentage change (mean \pm SEM) in frequency, amplitude, rise time, and decay time of SEPSCS after application of TNF $\alpha$ with $(n=8)$ and without $(n=11)$ bath application of bicuculline and strychnine. ${ }^{* *} p<0.01$ compared with baseline before application of TNF $\alpha$ (Student's paired $t$ test).

et al., 1998, 1999; Moore et al., 2002), the present study is focused on better defining the mechanisms underlying the modulation of synaptic transmission in SG induced by TNF $\alpha$ and to test the hypothesis that p38 is an important second messenger in mediating its effects in spinal cord. Whole-cell patch-clamp and immunohistochemical approaches are used to define the physiological effects of TNF $\alpha$ on subgroups of SG neurons, the receptors mediating these effects, their anatomical localization, and the involvement of p38 in transduction of these signals.

\section{Materials and Methods}

Animals. Adult FVB/NJ (4-6 weeks old; The Jackson Laboratory) and CB6-Tg (Gad1-EGFP) G42Zjh/J mice of either sex were used (The Jackson Laboratory). Mice were housed under a $12 \mathrm{~h}$ light/dark cycle with access to food and water ad libitum. All experiments were approved by the Institutional Animal Care and Use Committee at the University of Texas MD Anderson Cancer Center and were performed in accordance with the National Institutes of Health Guidelines for Use and Care of Laboratory Animals.
Spinal cord slice preparation. Spinal cord slices were prepared as described previously (Zhang et al., 2009). Briefly, mice were deeply anesthetized with inhaled isoflurane (3\%). A laminectomy was performed, and the lumber spinal cord was quickly removed and placed into ice-cold oxygenated $\left(95 \% \mathrm{O}_{2} / 5 \% \mathrm{CO}_{2}\right)$ artificial CSF solution containing the following (in $\mathrm{mm}$ ): 117 sucrose, $3.6 \mathrm{KCl}, 1.2 \mathrm{NaH}_{2} \mathrm{PO}_{4}$, $1.2 \mathrm{MgCl}_{2}, 2.5 \mathrm{CaCl}_{2}, 25 \mathrm{NaHCO}_{3}$, and $12 \mathrm{glu}-$ cose. The pia-arachnoid membrane was carefully peeled off, and a block of the spinal cord from L3 to S1 was embedded in $4 \%$ agar. Transverse slices (300 $\mu \mathrm{m}$ thick) from lumber segments L4-L5 were cut on a vibratome (series 1000; Technical Products International). The slices were then returned to bubbled Krebs' solution (in mm: $117 \mathrm{NaCl}, 3.6 \mathrm{KCl}, 1.2$ $\mathrm{NaH}_{2} \mathrm{PO}_{4}, 1.2 \mathrm{MgCl}_{2}, 2.5 \mathrm{CaCl}_{2}, 12$ glucose, and $25 \mathrm{NaHCO}_{3}$ ) at room temperature $\left(\sim 22^{\circ} \mathrm{C}\right)$ and allowed to equilibrate at least for $1 \mathrm{~h}$ before recording. The mice were killed by anesthetic overdose and exsanguination.

Patch-clamp recording in spinal slices. Whole-cell patch-clamp recordings from spinal SG neurons were obtained as described previously (Zhang et al., 2009). An individual slice was transferred to a recording chamber and continually perfused with oxygenated Krebs' solution $(3 \mathrm{ml} / \mathrm{min})$ at room temperature. SG cells were visualized using a $60 \times$ waterimmersion objective on an upright microscope (BX50WI; Olympus) equipped with infrared and differential interference contrast (DIC) optics. Patch pipettes were made from borosilicate glass (World Precision Instruments) with resistances of 3-5 $\mathrm{M} \Omega$ when filled with pipette solutions containing the following (in $\mathrm{mm}$ ): $145 \mathrm{~K}$-gluconate, $5 \mathrm{NaCl}, 1 \mathrm{MgCl}_{2}, 0.2 \mathrm{EGTA}$, 10 HEPES, $2 \mathrm{Mg}$-ATP, and $0.1 \mathrm{Na}_{3}$-GTP, pH 7.2 adjusted with $\mathrm{KOH}$, for spontaneous EPSC (sEPSC) recording; or $120 \mathrm{Cs}_{2} \mathrm{SO}_{4}, 5 \mathrm{NaCl}, 1$ $\mathrm{MgCl}_{2}, 0.5$ EGTA, 10 HEPES, $2 \mathrm{Mg}$-ATP, and $0.1 \mathrm{Na}_{3}$-GTP, pH 7.2 adjusted with $\mathrm{CsOH}$, for spontaneous IPSC (sIPSC) recording. After establishing the whole-cell configuration, membrane currents were measured with the patchclamp technique (Hamill et al., 1981). Neurons were held at $-70 \mathrm{mV}$ for EPSC recordings and $0 \mathrm{mV}$ for IPSC recording. Signals were amplified using a Multiclamp 700B amplifier (Molecular Devices), filtered at $2-5 \mathrm{kHz}$, and sampled at $10 \mathrm{kHz}$ in digital forms using a Digidata $1322 \mathrm{~A}$ digitizing board (Molecular Devices) interfaced with a computer system. Access resistance, typically 15-30 M $\Omega$, was measured on establishment of whole-cell configuration and throughout each recording. Cells were abandoned if access resistance changed $>20 \%$. The input resistance $\left(R_{\text {in }}\right)$ of the cell was calculated based on the steady-state current change during application of a $10 \mathrm{mV}$ depolarizing and/or $10 \mathrm{mV}$ hyperpolarizing pulse. The membrane capacitance $\left(C_{\mathrm{m}}\right)$ was calculated from the transient currents observed during the application of a $10 \mathrm{mV}$ depolarizing or hyperpolarizing pulse, using a single spherical compartment model. The resting membrane potential $\left(V_{\mathrm{m}}\right)$ was recorded in current-clamp mode. Leak subtraction, capacitance, and series resistance compensation were generally not applied except when otherwise noted.

Immunohistochemistry. Animals were deeply anesthetized with pentobarbital sodium (Nembutal, $100 \mathrm{mg} / \mathrm{kg}$, i.p.) and perfused through the ascending aorta with warm saline, followed by cold $4 \%$ paraformaldehyde in $0.1 \mathrm{M}$ phosphate buffer. The L4-L5 spinal cord segments were 
removed and postfixed in $4 \%$ paraformaldehyde for $4 \mathrm{~h}$ and then cryoprotected in $30 \%$ sucrose solution at $4^{\circ} \mathrm{C}$ for at least one night. Transverse free-floating spinal cord sections $(20 \mu \mathrm{m})$ were cut in a cryostat and processed for immunofluorescent staining. Thirty sections per mouse were used unless otherwise stated. Double-immunofluorescence labeling was used to study the distribution of TNF $\alpha$ receptors and phosphorylated p38 (pp38) MAPK in spinal dorsal horn cells. All of the sections were first blocked with $10 \%$ normal donkey serum (NDS) and $0.2 \%$ Triton $\mathrm{X}-100$ in PBS for $1 \mathrm{~h}$ at room temperature. The sections were then incubated over two nights at $4^{\circ} \mathrm{C}$ in $5 \%$ NDS and $0.2 \%$ Triton $\mathrm{X}-100$ in PBS containing the primary antibodies for the following targets: TNF receptor 1 (TNFR1) (rabbit, 1:1000; Abcam), TNFR2 (rabbit, 1:500; Abcam), GFAP (mouse, 1:1000; Cell Signaling Technology), neuronal-specific nuclear protein (NeuN) (mouse, 1:1000; Millipore), microtubule-associated protein 2 (MAP2) (mouse, 1:1000; Millipore), and CD11b (rat, 1:500; Serotec). The sections were then incubated with cyanine 3 (Cy3)- or FITCconjugated secondary antibodies in 5\% NDS and $0.2 \%$ Triton $\mathrm{X}-100$ overnight at $4^{\circ} \mathrm{C}$. For double-immunofluorescent staining, sections were incubated with two different primary antibodies, followed by a mixture of appropriate Cy3- and FITC-conjugated secondary antibodies. For p-p 38 staining, spinal cord slices $(300 \mu \mathrm{m})$ were first prepared as described in patch-clamp recordings in spinal slices. After equilibrating in oxygenated Krebs' solution at least for $1 \mathrm{~h}$ at room temperature, slices were stimulated with TNF $\alpha(10 \mathrm{ng} / \mathrm{ml})$ for 5 or 30 min. Slices were then postfixed in $4 \%$ paraformaldehyde for $4 \mathrm{~h}$ and cryoprotected in $30 \%$ sucrose overnight at $4^{\circ} \mathrm{C}$. For immunohistochemical staining, slices were first incubated with $10 \%$ NDS and $1 \%$ Triton X-100 for 30 min, followed by $10 \%$ NDS and $0.2 \%$ Triton $\mathrm{X}-100$ for $1 \mathrm{~h}$ at room temperature. Slices were then incubated over two nights at $4^{\circ} \mathrm{C}$ with anti-p-p38 antibody (rabbit, 1:100; Cell Signaling Technology) and Alexa Fluor 488conjugated anti-GFAP antibody (mouse, 1:500; Cell Signaling Technology) or Alexa Fluor 488-conjugated anti-NeuN antibody (mouse, 1:500; Millipore) or Alexa Fluor 488-conjugated anti-CD11b antibody (mouse, 1:100; Serotec). After washing with PBS, slices were incubated with Cy3-conjugated secondary antibody overnight at $4^{\circ} \mathrm{C}$. Slices were then mounted on glass coverslips and were viewed under a confocal microscope (FV5, FluoView V5.0; Olympus). To quantify the level of p-p38 in the spinal cord, the brightness of fluorescent staining in spinal cord dorsal horn (laminas I-II) was measured from images captured under $20 \times$ objective. Ten to 20 slices from L4-L5 spinal cord segments were randomly selected for each treatment. For each slice, background was first subtracted to differentiate positively stained cells, and the brightness of all positive cells in laminas I-II was measured. The area of spinal lamina I-II was determined when the slice was viewed under DIC. For a given experiment, the exposure times and illumination intensities were identical when images were captured. All images were analyzed using NIC Elements imaging software (Nikon).

Chemicals. 6,7-Dinitroquinoxaline-2, 3-dione (DNQX) and D-2-amino5-phosphonopentanoic acid (D-AP-5) were obtained from Tocris Biosciences. Recombinant mouse TNF $\alpha$ was purchased from R \& D Systems
C

Control

DNQX 10uM + D-AP5 $25 u M$

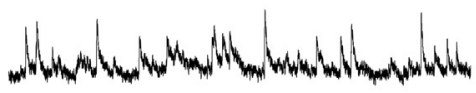

b

TNFa $10 \mathrm{ng} / \mathrm{ml}$

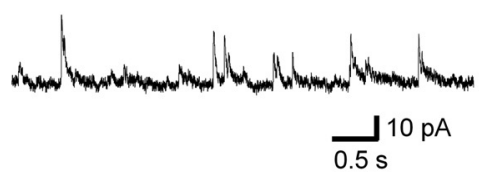

C

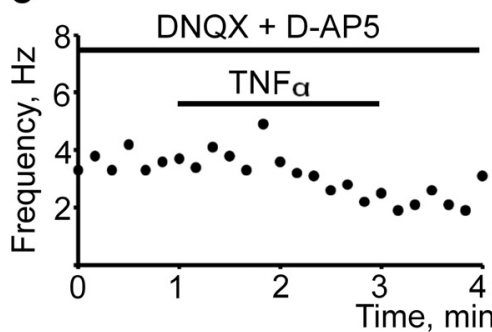

D

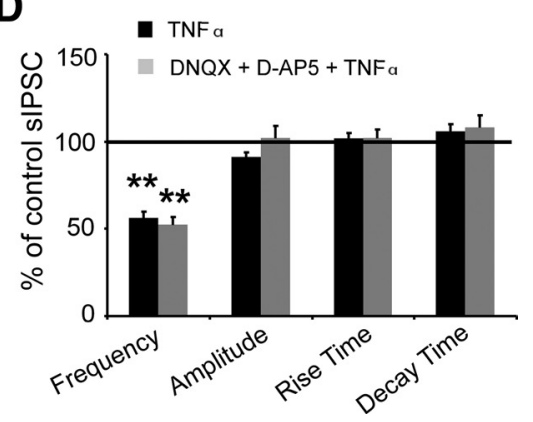

Figure 2. TNF $\alpha(10 \mathrm{ng} / \mathrm{ml}, 2 \mathrm{~min})$ suppresses inhibitory synaptic transmission in spinal dorsal horn. $A$, sIPSCs recorded from a

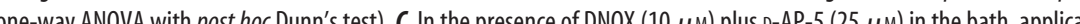
${ }_{\mathrm{TNF}} \alpha$ still decreased the frequency of sIPSCS. D, Grouped data showed the percentage change (mean \pm SEM) in frequency, amplitude, rise time, and decay time of sIPSCs after application of TNF $\alpha$ with $(n=12)$ and without $(n=22)$ bath application of DNQX and D-AP-5. ${ }^{* *} p<0.01$ compared with baseline before application of TNF $\alpha$ (Student's paired $t$ test).

and prepared as stock solutions at $10 \mu \mathrm{g} / \mathrm{ml}$ in PBS with $0.1 \%$ BSA. TNF $\alpha$ receptor antagonizing antibodies were kind gifts from Dr. Bharat Aggarwal (University of Texas MD Anderson Cancer Center, Houston, TX). SB202190 [4-(4-fluorophenyl)-2-(4-hydroxyphenyl)-5-(4-pyridyl) $1 \mathrm{H}$ imidazole] and its inactive analog SB202474 [4-ethyl-2( $p$ methoxyphenyl)-5-( $4^{\prime}$-pyridyl)-1 $H$-imidazole] were obtained from Calbiochem and dissolved in DMSO (final concentration $<0.1 \%$ ). All other chemicals were obtained from Sigma-Aldrich unless otherwise noted.

Statistical analysis. All results are presented as means \pm SEM. Differences between means were tested for significance using Student's paired $t$ test or ANOVA with an $\alpha$ value of $p<0.05$.

\section{Results}

TNF $\alpha$ increases excitatory synaptic transmission by suppressing inhibitory synaptic transmission in spinal dorsal horn

sEPSCs and sIPSCs were recorded from randomly selected SG neurons. The effect of TNF $\alpha$ on excitatory synaptic transmission 
A

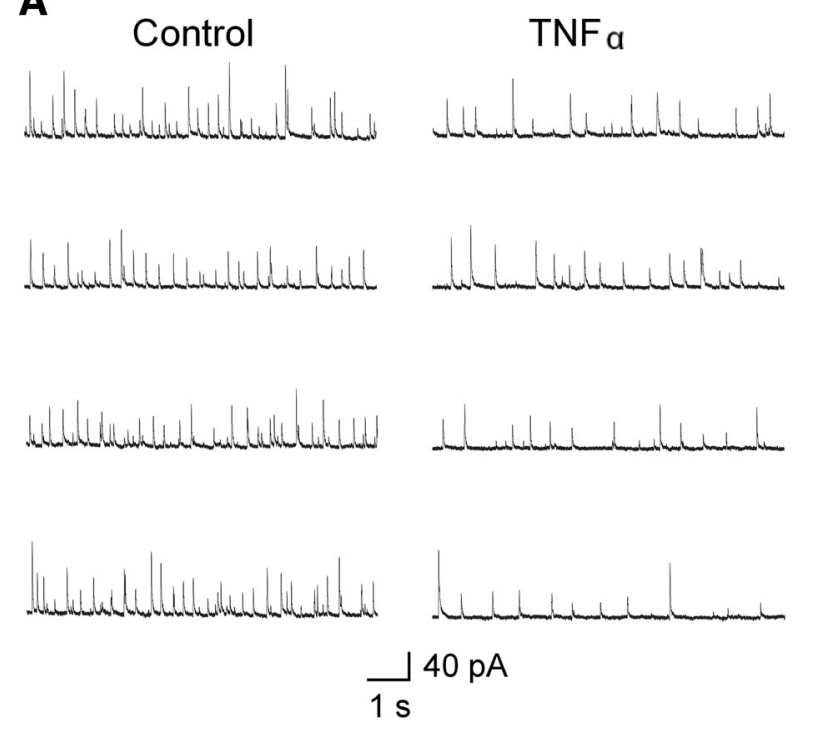

B

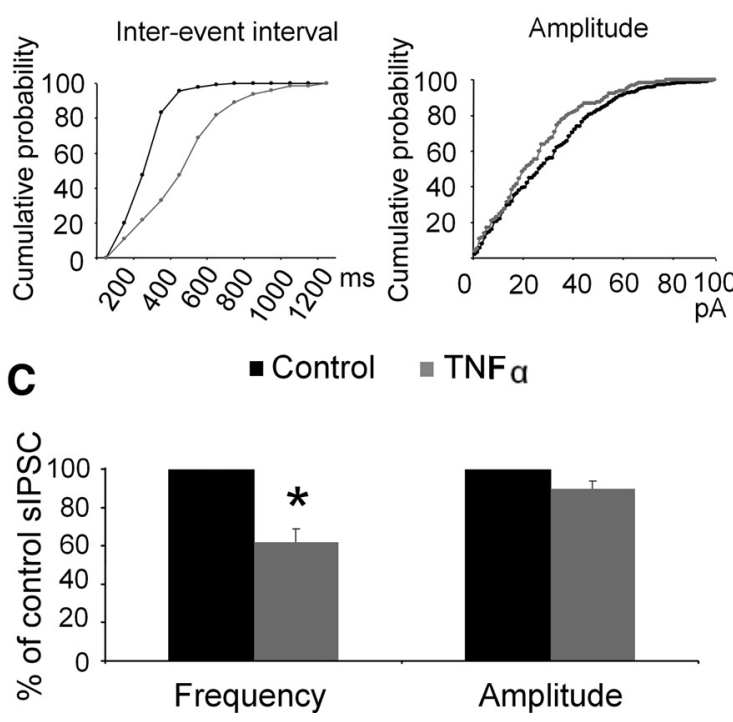

Figure 3. TNF $\alpha(10 \mathrm{ng} / \mathrm{ml}, 2 \mathrm{~min})$ decreases the frequency of mIPSC in spinal dorsal horn. $\boldsymbol{A}$, Examples of mIPSCs before and after the application of TNF $\alpha$. $\boldsymbol{B}$, Cumulative probability of mIPSC interevent interval and amplitude from the same cell shows a significant rightward shift in the distribution of interevent interval but only a slight leftward shift in the distribution of amplitude after $\operatorname{TNF} \alpha$ treatment (black, before TNF $\alpha$; gray, after TNF $\alpha$ ). C, TNF $\alpha$ significantly decreases the frequency but not the amplitude of $\mathrm{mIPSC}(n=7) .{ }^{*} p<0.05$ compared with baseline before application of TNF $\alpha$ (Student's paired $t$ test).

was tested first. Rapid bath application of TNF $\alpha$ (10 ng/ml, 2 min) significantly increased the frequency of sEPSCs in 11 of 14 recorded neurons, to $158.3 \pm 15.0 \%$ of control (from $2.4 \pm 0.6$ to $3.3 \pm 0.7 \mathrm{~Hz} ; n=11 ; p<0.005$ ) (Fig. $1 A, D)$. TNF $\alpha$ had no effect on other characteristics of sEPSCs, including amplitude, rise time, or decay time constant (Fig. 1D). Because capacitance and series resistance were not compensated, subtle changes in rise time kinetics induced by TNF may not have been observed. TNF $\alpha$ evoked greater enhancement in sEPSCs when tested at 50 $\mathrm{ng} / \mathrm{ml}$, but no effect was observed at a concentration of $1 \mathrm{ng} / \mathrm{ml}$ (Fig. $1 B$ ). The frequency of sEPSCs was increased to $237.3 \pm$ $12.4 \%$ of control $(n=4$ of $5 ; p<0.01)$ at $50 \mathrm{ng} / \mathrm{ml} \mathrm{TNF} \alpha$ but did not change at $1 \mathrm{ng} / \mathrm{ml} \mathrm{TNF} \alpha(99.8 \pm 18.7 \%$ of control; $n=5)$. These findings are consistent with the previously reported enhancement of excitatory synaptic transmission in SG neurons induced by TNF $\alpha$ (Kawasaki et al., 2008).

Spinal SG is composed of both excitatory and inhibitory neurons interconnected in a complicated but not fully characterized circuit, yet the overall valence in the circuit is considered inhibitory. Hence, the increased frequency of sEPSCs by TNF $\alpha$ was initially hypothesized as attributable to alterations in inhibitory processes. To test this hypothesis, the $\mathrm{GABA}_{\mathrm{A}}$ receptor blocker (bicuculline, $10 \mu \mathrm{M}$ ) and the glycine receptor blocker (strychnine, $5 \mu \mathrm{M}$ ) were added to the bath before the application of TNF $\alpha$. The addition of bicuculline and strychnine significantly increased the frequency of sEPSCs in 8 of 10 cells from $2.8 \pm 0.1$ to $3.7 \pm 0.2 \mathrm{~Hz}(n=8 ; p<0.01)$. TNF $\alpha$ added after bicuculline and strychnine resulted in no additional change in the frequency of sEPSCs when inhibitory synaptic transmission was blocked $(n=8)$ (Fig. 1C,D).

These results suggested that TNF $\alpha$ increases sEPSCs in SG by inhibiting sIPSCs. Indeed TNF $\alpha$ was found to produce a robust inhibitory effect of sIPSCs in SG neurons. In 22 of 23 recorded neurons, bath application of TNF $\alpha(10 \mathrm{ng} / \mathrm{ml}, 2 \mathrm{~min})$ significantly decreased the frequency of sIPSCs to $55.4 \pm 4.4 \%$ of control (from $7.2 \pm 1.0$ to $3.0 \pm 0.5 \mathrm{~Hz} ; n=22 ; p<0.01$ ) (Fig. $2 A, D)$. This inhibitory effect of TNF $\alpha$ on sIPSCs was also dose dependent, with significant inhibitory effect seen at 10 and 50 but not $1 \mathrm{ng} / \mathrm{ml} \mathrm{TNF} \alpha$ (Fig. $2 B$ ). The frequency of sIPSCs was decreased to $25.1 \pm 5.5 \%$ of control $(n=5 ; p<0.05)$ at $50 \mathrm{ng} / \mathrm{ml}$ TNF $\alpha$, reaching the maximal inhibition. To test whether the inhibitory effect of TNF $\alpha$ on sIPSCs was dependent on the excitatory synaptic transmission, the AMPA-kainate receptor blocker $\operatorname{DNQX}(10 \mu \mathrm{M})$ and the NMDA receptor blocker D-AP-5 (25 $\mu \mathrm{M})$ were added into the bath before the application of TNF $\alpha$. As shown in Figure 2, $C$ and $D$, the inhibitory effect of TNF $\alpha$ on sIPSCs persisted during blockade of excitatory synaptic transmission as the frequency was reduced to $52.4 \pm 5.4 \%$ of control for the 12 of 14 neurons tested (from $2.1 \pm 0.4$ to $1.2 \pm 0.3 \mathrm{~Hz} ; n=$ $12 ; p<0.001)$. In either condition, $\mathrm{TNF} \alpha$ had no effect on the amplitude, rise time, or decay time constant of sIPSCs (Fig. 2D).

In addition to suppressing sIPSCs, TNF $\alpha$ was also found to suppress miniature IPSCs (mIPSCs). TNF $\alpha$ at $10 \mathrm{ng} / \mathrm{ml}$ significantly decreased the frequency of mIPSCs to $61.6 \pm 6.9 \%$ (from $3.8 \pm 0.8$ to $2.4 \pm 0.7 \mathrm{~Hz} ; n=7 ; p<0.05$ ) (Fig. $3 A, C$ ), and there was a strong rightward shift in the cumulative interevent interval distribution (Fig. 3B). The amplitude of mIPSCs was decreased but did not reach statistical significance (Fig. $3 B, C$ ).

TNF $\alpha$ induces disinhibition in synaptic transmission through activation of TNFR1

TNF $\alpha$ exerts its action through two receptors, TNFR1 (p55) and TNFR2 (p75) (Tartaglia et al., 1991; Tartaglia and Goeddel, 1992), with the majority of the its effects being transmitted through TNFR1 (Vandenabeele et al., 1995). TNFR1 and TNFR2 are expressed in both the PNS and CNS (Shubayev and Myers, 2001; Pollock et al., 2002; Holmes et al., 2004). The roles of these receptors in TNF $\alpha$-induced suppression of sIPSCs in SG neurons were defined in experiments using spinal slices preincubated with antagonizing antibodies to either TNFR1 or TNFR2 (Higuchi and Aggarwal, 1992). As shown in Figure 4, TNF $\alpha$ had no effect on sIPSCs when spinal slices were preincubated with antagonizing antibody to TNFR1 $(1: 500 ; n=13)$ (Fig. $4 A, C)$. In contrast, TNF $\alpha$ caused a significant decrease in the frequency of sIPSCs 
when spinal slices were preincubated with antagonizing antibody to TNFR2 (1:500; $55.6 \pm 7.2 \%$ of control; $n=11 ; p<0.001)$ (Fig. $4 B, C$ ). This suggests that TNF $\alpha$ inhibits spinal inhibitory synaptic transmission via the activation of TNFR1 not TNFR2.

Although it has been reported that TNF $\alpha$ receptors are generally expressed in spinal cord of naive animals (Holmes et al., 2004; Ohtori et al., 2004), the baseline expression and the exact location of TNF $\alpha$ receptors in naive animals is not clear. To address this question, the location of $\mathrm{TNF} \alpha$ receptors in spinal cord was determined by double-immunohistochemistry staining of TNFR1 or TNFR2 along with cellular markers for neurons (NeuN and MAP2), astrocytes (GFAP), and microglia (CD11b). The specificity of the antibodies used in the present study were defined previously (Khan et al., 2008; Vince et al., 2009). TNFR1 was confirmed to be expressed throughout the spinal cord gray matter, whereas TNFR2 was expressed only in ventral horn of naive mouse (Figs. $5 B, 6 B$, respectively). It was further observed that TNFR1 was expressed on astrocytes and spinal dorsal horn neurons but not microglia (Fig. 5C-F). In contrast, TNFR2 was only expressed in large ventral horn neurons that were consistent in location and morphology to motor neurons (Fig. 6C-F).

\section{TNF $\alpha$ induced disinhibition of spinal synaptic transmission is dependent on activation of p38 mitogen-activated protein kinase in spinal dorsal horn neurons}

p38 MAPK is activated in spinal cord after tissue injury and inflammation, and blockade of p38 MAPK activation prevents the development of neuropathic and inflammatory pain (Schäfers et al., 2003a; Svensson et al., 2005; Boyle et al., 2006; Sorkin et al., 2009). The possible involvement of p38 MAPK activation in mediating the effects of TNF $\alpha$ on spinal synaptic transmission was explored by examining the levels of active (phosphorylated) p38 (p-p38) in mouse spinal cord after treatment with TNF $\alpha$. Spinal cord slices were prepared and bathed with TNF $\alpha$ as in the electrophysiological recordings (10 $\mathrm{ng} / \mathrm{ml}$ in Krebs' solution for 5 or $30 \mathrm{~min}$ ) and then processed using double immunohistochemistry. As shown in Figure $7 A$, a modest baseline expression of p-p38 was confirmed present in superficial dorsal horn in control slices (Svensson et al., 2008). Application of TNF $\alpha$ was found here to induce a marked increase of p-p38 expression in spinal dorsal horn of slices incubated with TNF $\alpha$ for as little as $5 \mathrm{~min}$, and $30 \mathrm{~min}$ treatment with TNF $\alpha$ further increased the expression of p-p38 (Fig. $7 B-D$ ). The cellular distribution of p-p38 was primarily colocalized with the neuronal marker NeuN (Fig. 7E) and only to a much less extent with the astrocytic marker GFAP (Fig. 7F). No coexpression of p-p38 was observed with the microglial marker CD11b (Fig. 7G).
B a

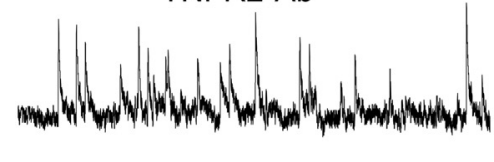

b

TNFa

NFR1-Ab

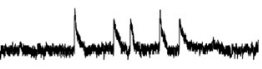

$\prod_{0.5 \mathrm{~s}} 10 \mathrm{pA}$

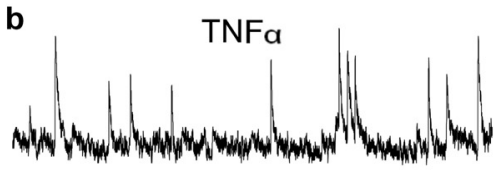

C

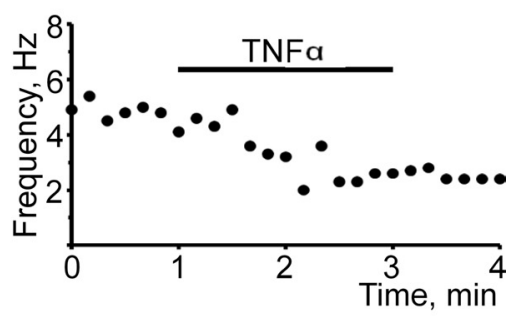

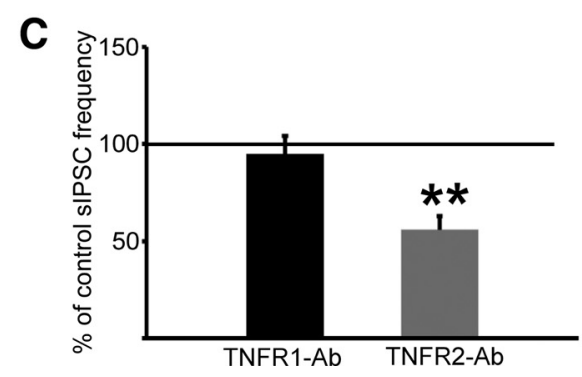

Figure 4. The inhibitory effect of TNF $\alpha$ on sIPSCs in spinal dorsal horn was mediated by the activation of TNFR1 but not TNFR2. fine recording time in the reprative neuron in $\boldsymbol{a}$ and $\boldsymbol{b}$. Frequency was measured every $10 \mathrm{~s}$. $\boldsymbol{C}$, Averaged dat showed that neutralizing TNFR1 ( $n=13)$ but not TNFR2 ( $n=11)$ prevented the inhibitory effect of TNF $\alpha$ on sIPSCs. ${ }^{* *} p<0.01$ compared with baseline before application of TNF $\alpha$ (Student's paired $t$ test).

The involvement of p38 in mediating the effects of TNF $\alpha$ was further explored by testing the effect of TNF $\alpha$ on sIPSCs in SG neurons using spinal cord slices preincubated with the p38 inhibitor SB202190 $(20 \mu \mathrm{M})$. The spinal slices were incubated with antagonist beginning at least $30 \mathrm{~min}$ before recording and perfused with antagonist throughout each experiment. As shown in Figure 8, TNF $\alpha$ had no effect on sIPSCs when $\mathrm{p} 38$ was blocked by SB202190 $(n=15)$. In contrast, TNF $\alpha$ significantly decreased the frequency of sIPSCs in slices pretreated with SB202474 $(20 \mu \mathrm{M})$, an inactive structural analog of SB202190 (Lee et al., 1994) $(n=5$; $p<0.005)$.

TNF $\alpha$ inhibits spontaneous action potentials in GABAergic neurons in spinal dorsal horn by reducing hyperpolarization-activated $\left(I_{h}\right)$ currents

The inhibitory effect of TNF $\alpha$ on sIPSCs suggested that the outputs from inhibitory neurons with spontaneous activity (SA) are decreased by TNF $\alpha$ treatment. The effect of TNF $\alpha$ on the activity of identified spinal GABAergic neurons was tested to examine this possibility. Transgenic mice expressing the "enhanced" derivative of green fluorescent protein (EGFP) at the upstream reg- 

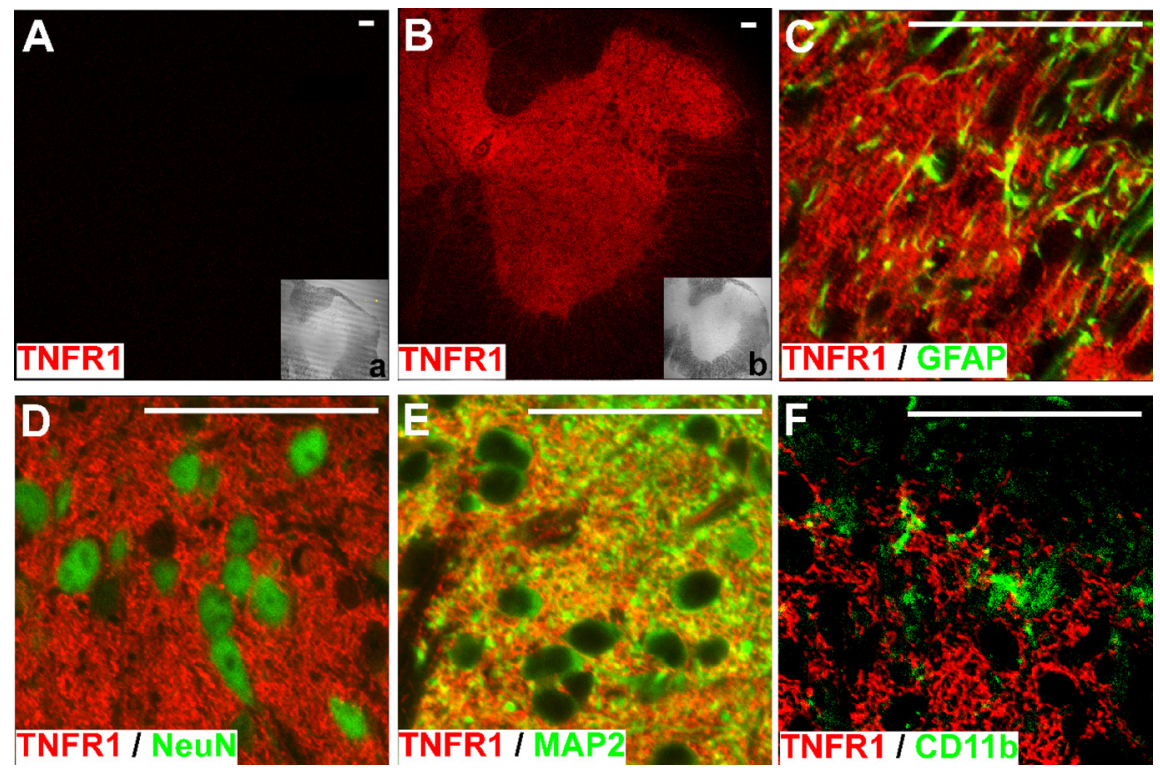

Figure 5. Localization of TNFR1 in spinal cord of naive mice. $A$, A negative control for TNFR1 staining when the primary antibody to TNFR1 is not added; $\boldsymbol{B}$, TNFR1 is expressed throughout the spinal cord gray matter. $\boldsymbol{a}, \boldsymbol{b}$, View of the slices under the light microscope. $C$, Double immunofluorescence in spinal dorsal horn shows colocalization of TNFR1 (red) and GFAP, an astrocyte marker (green). D, Double immunofluorescence in spinal dorsal horn shows no colocalization of TNFR1 (red) and NeuN, a neuronal soma marker (green). $\boldsymbol{E}$, Double immunofluorescence shows colocalization of TNFR1 (red) and MAP2, a neuronal dendrite marker (green). $\boldsymbol{F}$, Double immunofluorescence shows no colocalization of TNFR1 (red) and (D11b, a microglia maker (green). Scale bars, $5 \mu \mathrm{m}$.
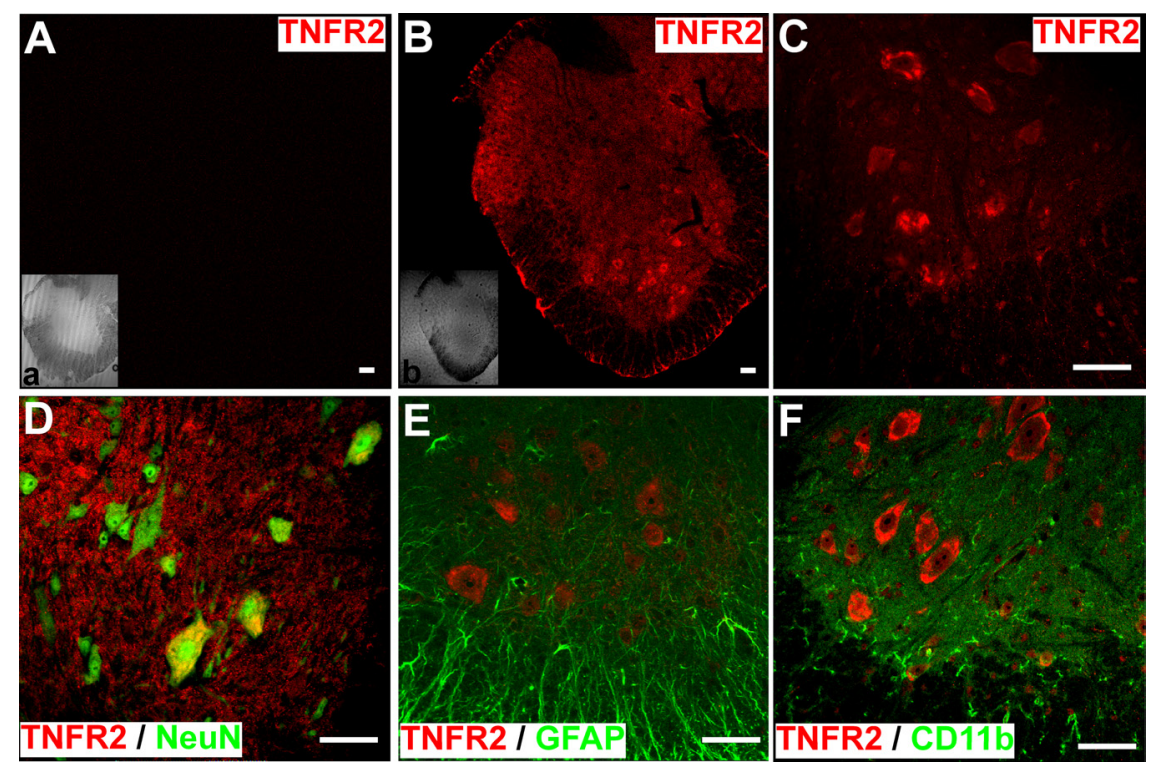

Figure 6. Localization of TNFR2 in spinal cord of naive mice. $A$, A negative control for TNFR2 staining when the primary antibody to TNFR1 is not added; $\boldsymbol{a}$, view of the same slice under the light microscope. $\boldsymbol{B}$, TNFR2 is expressed predominantly in spinal cord ventral horn; $\boldsymbol{b}$, view of the same slice under the light microscope. $\boldsymbol{C}$, A magnifying view shows TNFR2 is expressed in spinal ventral horn neurons. $\boldsymbol{D}-\boldsymbol{F}$, Double immunofluorescence in spinal dorsal horn shows the colocalization of TNFR2 with NeuN (D) but not with GFAP $(\boldsymbol{E})$ or CD11b $(\boldsymbol{F})$. Scale bars, $5 \mu \mathrm{m}$.

ulatory sequence from the murine Gadl gene (encoding the GABA synthesizing enzyme GAD67) were used in these experiments. The EGFP-labeled neurons were observed throughout the CNS, including spinal cord dorsal horn (data not shown). Synaptic transmission was blocked by adding DNXQ $(10 \mu \mathrm{M})$, D-AP-5 $(25 \mu \mathrm{M})$, bicuculline $(10 \mu \mathrm{M})$, and strychnine $(5 \mu \mathrm{M})$ in the bath. GABAergic neurons were first studied in cell-attached mode. As shown in Figure 9A, a subset of GABAergic neurons (4 of 10) displayed intrinsic SA that was independent of synaptic transmission. Rapid application of TNF $\alpha$ inhibited this spontaneous activity, reducing the frequency of SA from $6.8 \pm 0.9$ to $3.2 \pm 0.4$ $\mathrm{Hz}(n=3 ; p<0.01)$. In whole-cell patchclamp recordings, 8 of 25 recorded GABAergic neurons displayed intrinsic SAs, and TNF $\alpha$ significantly decreased the frequency of SAs in six neurons from $3.8 \pm 0.3$ to $1.5 \pm 0.2 \mathrm{~Hz}(n=6 ; p<$ 0.001) (Fig. 9B). To examine whether the inhibitory effect of TNF $\alpha$ on GABAergic neurons is mediated by p38 MAPK, SB202190 $(20 \mu \mathrm{M})$ was added to patch pipette solution in another series of experiments. As shown in Figure 9C, TNF $\alpha$ no longer had any inhibitory effect on GABAergic neurons when p38 MAPK was blocked inside the recorded cells $(n=4)$, strongly suggesting that intraneuronal activation of p38 MAPK-dependent pathway is involved in the modulation of neuronal activities induced by TNF $\alpha$.

The rapid inhibitory effect of TNF $\alpha$ on GABAergic neurons suggests a modulation of basic ionic mechanisms of spike generation. Superimposition of action potential spikes recorded before and after application of TNF $\alpha$ revealed minimal effects on the properties of action potential waveforms (Fig. 10 Aa) but revealed significantly prolonged interspike intervals resulting in the attenuation of firing frequency of GABAergic neurons (Fig. 10Ab). TNF $\alpha$ reduced the slope of the depolarization ramp leading to action potential threshold, suggesting a possible decrease of the hyperpolarization-activated cation current $\left(I_{\mathrm{h}}\right)$. To study the effect of TNF $\alpha$ on $I_{\mathrm{h}}$ currents of GABAergic neurons, cells were held at resting membrane potential and then hyperpolarized by a long current test pulse $(200 \mathrm{pA}, 2 \mathrm{~s})$. A slow depolarizing "sag" was elicited during a time-dependent inward rectification after the hyperpolarization and represented the activation of $I_{\mathrm{h}}$ current (Harris et al., 1989; Harris, 1992). A sag current was elicited by hyperpolarizing currents in 14 of 16 GABAergic neurons (Fig. $10 \mathrm{Ba}$, black arrow) but only in 4 of 22 non-EGFP (GAD67 negative) neurons, suggesting that $I_{\mathrm{h}}$ current is predominantly expressed in GABAergic neurons. The application of $\mathrm{TNF} \alpha(10 \mathrm{ng} / \mathrm{ml})$ reduced the sag current in 9 of 11 GABAergic neurons (Fig. $10 B a$, red arrow, $B b$ ) but only in 1 of 4 nonEGFP neurons showing a sag current. Hyperpolarizationinduced sag was often followed by a slow afterhyperpolarizing tail that was accompanied by rebound action potentials, reflecting activation of a transient outward current (Fig. 10 Ba) (Harris et al., 1989; Harris, 1992). TNF $\alpha$ also reduced the number of rebound action potentials from $9.2 \pm 0.8$ to $3.1 \pm 0.5(n=$ 

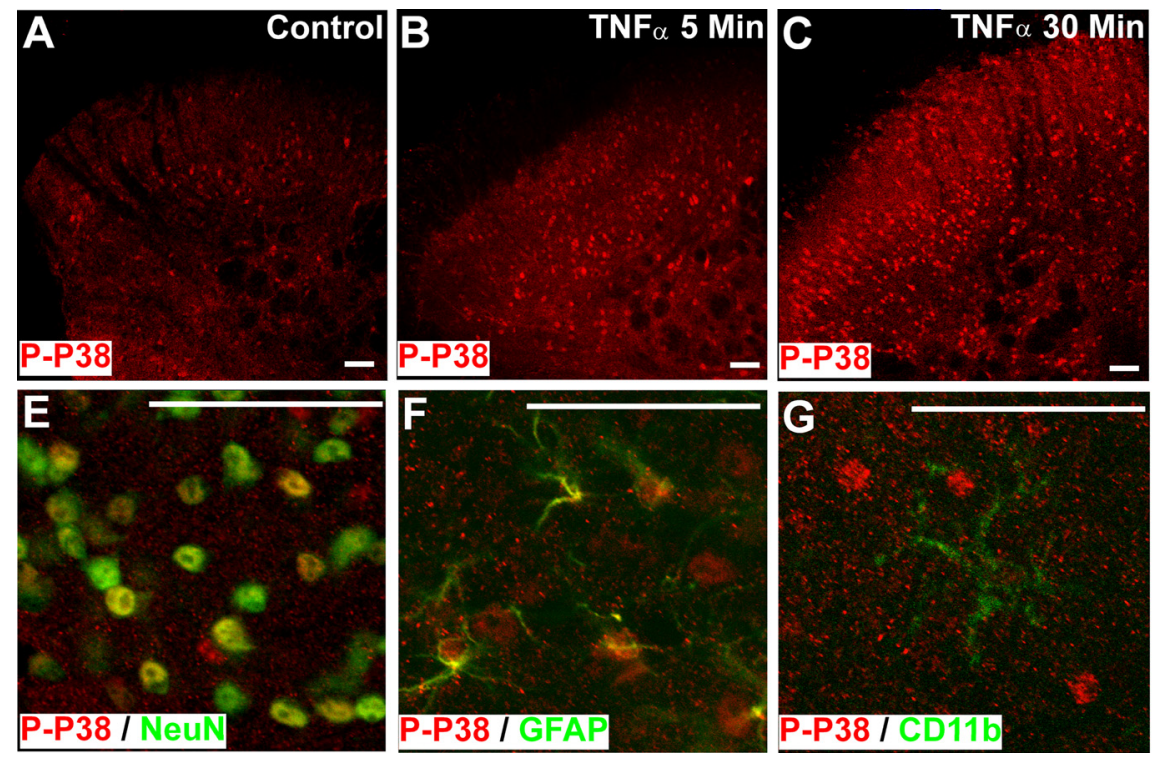

D

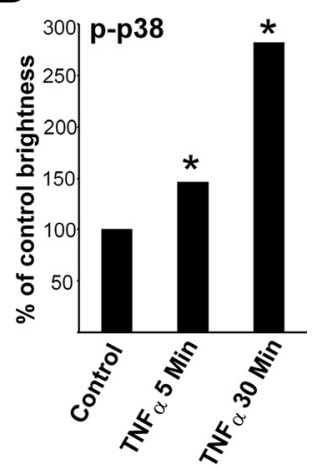

Figure 7. Expression of $p$-p38 in spinal dorsal horn induced by the application of TNF $\alpha$. $A, A$ baseline expression of $p$-p38 is detected in spinal dorsal horn in naive mice. $\boldsymbol{B}, \boldsymbol{C}, A$ robust increase in p-p38 expression in spinal dorsal horn is detected after spinal slices are incubated with TNF $\alpha(10 \mathrm{ng} / \mathrm{ml})$ for 5 and 30 min, respectively. $\boldsymbol{D}$, The expression of $p$-p 38 in spinal dorsal horn with different treatment was quantified and represented as percentage of control. Both $5 \mathrm{~min}(n=15)$ and $30 \mathrm{~min}(n=18)$ treatment with TNF $\alpha$ significantly increased the expression of $p$-p38 in spinal cord laminas I-II compared with control $(n=11)$. The expression of $p$-p38 was significantly increased after 30 min treatment of TNF $\alpha$ compared with 5 min treatment. ${ }^{*} p<0.01$, ANOVA. $\boldsymbol{E}-\mathbf{G}$, Double immunofluorescence shows that the expression of p-p38 is predominantly in neurons $(\boldsymbol{E})$ and in a small number of astrocytes $(\boldsymbol{F})$ but not in microglia $(\boldsymbol{G})$. Scale bars, $5 \mu \mathrm{m}$.

9; $p<0.01$ ) (Fig. $10 B a, B c$ ). The effect of TNF $\alpha$ on sag and rebound action potentials mimics the effect of ZD7288 (4ethylphenylamino-1,2-dimethyl-6-methylaminopyrimidinium chloride) $(50 \mu \mathrm{M} ; n=4)$ (Fig. 10C), a specific $I_{\mathrm{h}}$ blocker, suggesting that $\mathrm{TNF} \alpha$ has a selectivity for $I_{\mathrm{h}}$ in spinal GABAergic neurons.

\section{Discussion}

Several studies have revealed that both central and peripheral administration of TNF $\alpha$ induces mechanical allodynia and thermal hyperalgesia (Cunha et al., 1992; Perkins and Kelly, 1994; Woolf et al., 1997; Schäfers et al., 2003b,c; Wacnik et al., 2005; Jin and Gereau, 2006; Gao et al., 2009). The peripheral mechanisms of TNF $\alpha$-induced hypersensitivity have been well documented. TNF $\alpha$ promotes heat-induced calcitonin gene-related peptide release from nociceptor terminals in skin (Oprée and Kress, 2000 ), sensitizes peripheral A $\beta$ - and C-fibers (Junger and Sorkin, 2000; Liu et al., 2002; Zhang et al., 2002; Schäfers et al., 2003b), sensitizes TRPV1 of primary sensory neurons (Nicol et al., 1997), and enhances TTX-resistant sodium currents in isolated primary sensory neurons (Jin and Gereau, 2006). Although TNF $\alpha$ has been shown to modulate excitatory and inhibitory synaptic transmission in hippocampus in different ways in early studies (Stellwagen et al., 2005), potential spinal effects of TNF $\alpha$ had not been explored until recently when direct application of $\operatorname{TNF} \alpha$ was shown to enhance excitatory synaptic transmission and increase AMPA and NMDA-evoked EPSCs in spinal dorsal horn (Kawasaki et al., 2008). The increase in spontaneous excitatory synaptic transmission induced by TNF $\alpha$ shown in the present study is consistent with these previous observations. Importantly, it is further shown here that the enhancement of spinal excitatory synaptic transmission evoked by TNF $\alpha$ is attributable to inhibition of ongoing inhibitory synaptic transmission. The similar inhibitory effect of TNF $\alpha$ on miniature IPSCs of spinal dorsal horn with that in hippocampus suggested the decreased release of neurotransmitters from presynaptic terminals (Stellwagen et al.,
2005) and was consistent with the inhibitory effect of TNF $\alpha$ on presynaptic voltage-dependent calcium channels (Czeschik et al., 2008; Motagally et al., 2009). Disinhibitory processes in the dorsal horn have been claimed previously as important to the development and maintenance of neuropathic pain (Yaksh, 1989; Castro-Lopes et al., 1993; Sivilotti and Woolf, 1994; Ibuki et al., 1997; Eaton et al., 1998, 1999; Moore et al., 2002). Thus, the data shown here implicate TNF $\alpha$ as a potential mediator key to this process.

TNF $\alpha$ has two receptors: TNFR1 and TNFR2, with TNFR1 being the dominant pathway for the major effects of TNF $\alpha$ (Vandenabeele et al., 1995). Our data indicate that TNF $\alpha$-induced disinhibition of spinal synaptic transmission is mediated through TNFR1 but not TNFR2. TNFR1 but not TNFR2 was observed expressed in spinal dorsal horn neurons and astrocytes, and only the neutralizing antibodies to TNFR1 were found to block the effects of TNF $\alpha$ on SG neurons. These findings are in concert with previous suggestions that TNFR1 is the major receptor for TNF $\alpha$ in promoting pain signal processing after nerve injury or inflammation (Sommer et al., 1998b; Parada et al., 2003; Cunha et al., 2005; Jin and Gereau, 2006). The expression of TNFR1 on spinal dorsal horn neurons and astrocytes suggested that both types of cells could be activated by TNF $\alpha$ and may contribute to the downstream effects after TNF $\alpha$.

p38 MAPK has been shown to play an important role in the development of inflammatory and neuropathic pain (Ji et al., 2002; Jin et al., 2003; Svensson et al., 2003, 2005, 2008; Schäfers et al., 2003a; Tsuda et al., 2004; Boyle et al., 2006; Zhuang et al., 2007; Sorkin et al., 2009; Fitzsimmons et al., 2010). Although the activation of p38 in spinal cord has been suggested previously as mediating many effects of TNF $\alpha$ (Schäfers et al., 2003a; Svensson et al., 2005; Boyle et al., 2006), direct evidence at the spinal level has been lacking. The data shown here in which TNF $\alpha$-induced disinhibition of spinal synaptic transmission was prevented by blocking the activation of p38 and in which bath application of 
A

a

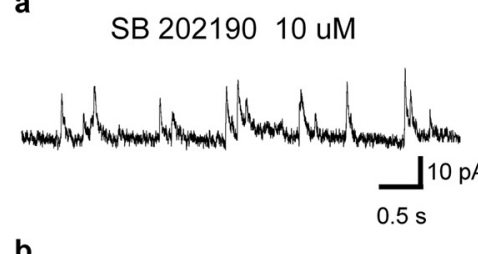

b

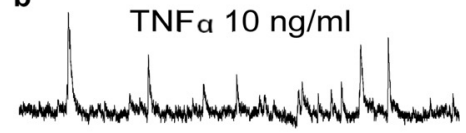

c

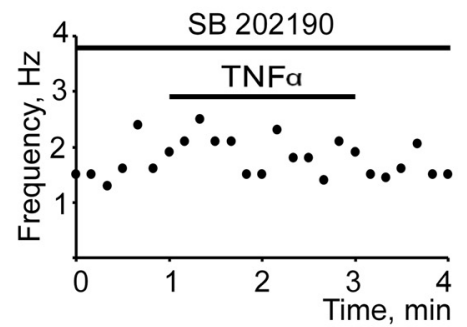

B

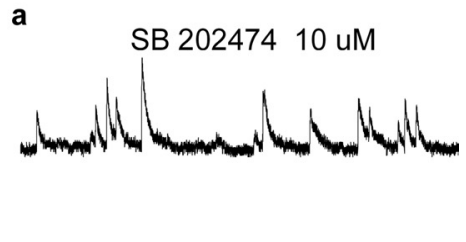

b

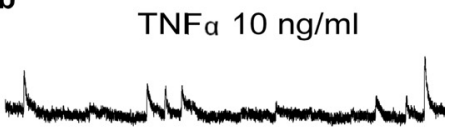

c

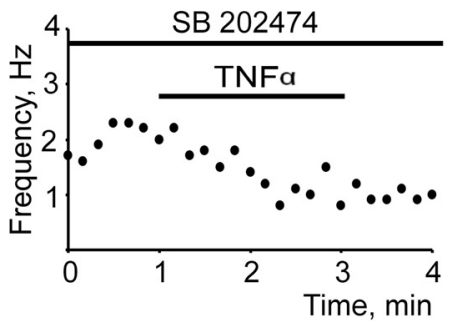

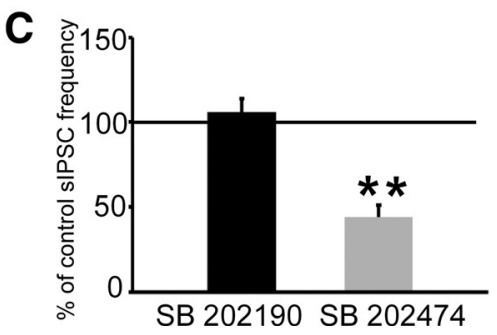

Figure 8. TNF $\alpha$-induced inhibition of spinal inhibitory synaptic transmission is mediated by the activation of p 38 MAPK. $\boldsymbol{A}$, The inhibitory effect of TNF $\alpha$ on sIPSCs was prevented by blocking the activation of $\mathrm{p} 38$. sIPSCs recorded from a spinal lamina II neuron before $(\boldsymbol{a})$ and after $(\boldsymbol{b})$ the application of TNF $\alpha$ when the slice was preincubated with SB202190, a p38 antagonist; $\boldsymbol{c}$, frequency of sIPSCs as a function of the recording time in the representative neuron in $\boldsymbol{a}$ and $\boldsymbol{b}$. $\boldsymbol{B}$. When the spinal slice was preincubated with SB202474, a p38 blocker inactive analog, application of TNF $\alpha$ significantly decreased the frequency of sIPSCs. Recordings of sIPSCs from a spinal lamina II neuron before $(\boldsymbol{a})$ and after $(\boldsymbol{b})$ the application of TNF $\alpha ; \boldsymbol{c}$, frequency of sIPSCs as a function of the recording time in the representative neuron in $\boldsymbol{a}$ and $\boldsymbol{b}$. Frequency was measured every $10 \mathrm{~s}$ in both $\boldsymbol{A}$ and $\boldsymbol{B}$. $\boldsymbol{C}$, Averaged data showed the percentage change of the frequency of sIPSCs after the application of TNF $\alpha$ when the slices were preincubated with SB202190 $(n=15)$ or SB202474 $(n=5) .{ }^{* *} p<0.01$ compared with baseline before application of TNF $\alpha$ (Student's paired $t$ test).

TNF $\alpha$ activated p38 predominantly in spinal dorsal horn neurons strongly implicate $\mathrm{p} 38$ as a key downstream mediator after TNF $\alpha-$ TNFR 1 activation. The TNF $\alpha-T N F R 1-p 38$ pathway may involve additional molecules, including ASK1, MEKK4, and possibly MKK3/6. Activated p38 is also translocated to the nucleus and can activate transcriptional factors such as ATF2, c-Jun, and CREB (Ji et al., 2009). In agreement with our data, it has been shown that application of TNF $\alpha$ increased the expression of activated CREB in spinal dorsal horn neurons (Kawasaki et al., 2008). Although activated $\mathrm{p} 38$ was exclusively observed in spinal microglia after nerve injury (Ji et al., 2002; Jin et al., 2003; Schäfers et al., 2003a; Svensson et al., 2005; Zhuang et al., 2007), the findings here that the activation of p38 was predominantly in spinal dorsal horn neurons and, to a much less extent, in spinal astrocytes is in line with other studies using inflammatory pain models (Boyle et al., 2006; Svensson et al., 2008; Sorkin et al., 2009). The variances in the pattern of p-p38 expression might reflect the different contributions of spinal neurons, astrocytes, and microglia to the development of pain under different initiating conditions of the various models or may simply reflect different expression patterns among the various cellular elements in the spinal cord over time.

The inhibitory tone in spinal cord dorsal horn is determined by the output from the inhibitory interneurons, including GABAergic and glycinergic neurons. Transgenic mice expressing EGFP in the upstream regulatory sequence from murine Gad1 gene (encoding the GABA synthesizing enzyme GAD67) (Chattopadhyaya et al., 2004) were used here to focus on a subgroup of identified GABAergic SG neurons. Under this condition, the labeled neurons account for approximately one-third of GABAergic population in spinal SG (Heinke et al., 2004). A population of these GABAergic neurons in spinal SG was found to exhibit spontaneous repetitive action potential firing. These discharges were observed to persist while synaptic inputs were blocked, indicating they were intrinsic to these neurons and suggesting that these subgroups provide tonic inhibitory tone within the dorsal horn. The inhibitory effect of TNF $\alpha$ on spontaneous firings of GABAergic neurons is consistent with the reduced spinal inhibitory synaptic transmission induced by TNF $\alpha$. The involvement of p38 in the TNF $\alpha$-induced inhibition of spontaneous firings of GABAergic neurons further supported previous data showing the role of p38 in mediating the TNF $\alpha$ induced inhibition on sIPSCs and the increased expression of p-p38 in spinal dorsal horn neurons after TNF $\alpha$. Together, these data clearly indicate that TNF $\alpha$ acting on TNFR1 on neurons is sufficient to suppress spontaneous action potentials in a subgroup of GABAergic neurons through a p38-mediated mechanism.

Hyperpolarization-activated cation currents $\left(I_{\mathrm{h}}\right)$, encoded by a family of genes called hyperpolarization-activated and cyclic nucleotide-sensitive cation nonselective $(\mathrm{HCN})$, has been identified in various central and peripheral neurons (Pape, 1996). Most of the spinal GABAergic neurons recorded here displayed $I_{\mathrm{h}}$ currents, in line with previous studies (Yoshimura and Jessell, 1989; Grudt and Perl, 2002; Hantman et al., 2004). HCN channel subunit 2 (HCN2) is widely expressed in spinal dorsal horn revealed by in situ hybridization and immunohistochemical approaches (Santoro et al., 2000; Papp et al., 2006). Because $I_{\mathrm{h}}$ current contributes to pacemaker activity (spontaneous repetitive action potential firing or rhythmic-oscillatory activity) in CNS neurons (McCormick and Pape, 1990; Maccaferri and McBain, 1996; Pape, 1996; Gasparini and DiFrancesco, 1997; Lüthi and McCormick, 1998), it may also modulate activities of GABAergic neurons in spinal dorsal horn. After the application of TNF $\alpha, I_{\mathrm{h}}$ currents of GABAergic neurons were decreased, suggesting that $\mathrm{TNF} \alpha$ may reduce the intrinsic spontaneous discharges of these GABAergic neurons through inhibition of $I_{\mathrm{h}}$ currents. The fact that ZD7288, a specific $I_{\mathrm{h}}$ 
current blocker, produced the same effect as of TNF $\alpha$ on inhibiting $I_{\mathrm{h}}$ current is in line with this conclusion. The data that only a small proportion of nonEGFP neurons have $I_{\mathrm{h}}$ currents suggests that this current may be useful in prospectively indentifying GABAergic neurons and hence focus the effects of TNF on these cells.

The expression of TNFR 1 and p-p38 in spinal astrocytes suggest that astrocytes could be involved in the TNF $\alpha$-induced spinal disinhibition. Spinal astrocytes have been found recently to actively contribute to the development of neuropathic pain after peripheral nerve injury (Zhuang et al., 2006; Gao et al., 2009). After activation, spinal astrocytes can release various molecules that can activate spinal dorsal horn neurons (for review, see Watkins and Maier, 2003). The data shown here revealed that the activation of the TNF $\alpha-$ TNFR $1-$ p38 pathway in spinal neurons is sufficient to induce the inhibition of spinal inhibitory transmission, but the possible role of spinal astrocytes cannot be excluded and may need additional study.

In conclusion, the present study suggests a unique cellular mechanism that mediates the modulation of spinal synaptic transmission induced by TNF $\alpha$. First, TNF $\alpha$ directly suppressed inhibitory synaptic transmission in spinal SG region, which consequently resulted in the enhancement of the excitatory synaptic transmission. Second, disinhibition of spinal synaptic transmission induced by TNF $\alpha$ was mediated by the activation of TNFR1 in spinal cord dorsal horn, followed by the activation of neuronal p38 MAPK. Third, GAD67 ${ }^{+}$GABAergic neurons in transgenic mice were found to display spontaneous intrinsic action potentials that were directly inhibited by $\mathrm{TNF} \alpha$ via a 38 -dependent pathway. This inhibition of spontaneous activities of GABAergic neurons was accompanied with a reduction of $I_{\mathrm{h}}$ currents, suggesting that $\mathrm{TNF} \alpha$ may inhibit neuronal activities through reducing $I_{\mathrm{h}}$ currents of GABAergic neurons. The cellular and molecular pathway underlying the TNF $\alpha$-induced spinal inhibition provides a presynaptic mechanism for central sensitization in the development and maintenance of neuropathic and inflammatory pain.

\section{References}

Boyle DL, Jones TL, Hammaker D, Svensson CI, Rosengren S, Albani S, Sorkin L, Firestein GS (2006) Regulation of peripheral inflammation by spinal p38 MAP kinase in rats. PLoS Med 3:e338.

Castro-Lopes JM, Tavares I, Coimbra A (1993) GABA decreases in the spinal cord dorsal horn after peripheral neurectomy. Brain Res 620:287-291. a

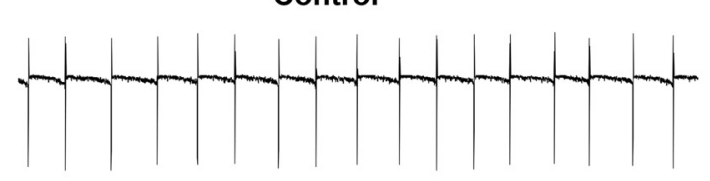

b

TNF $a$

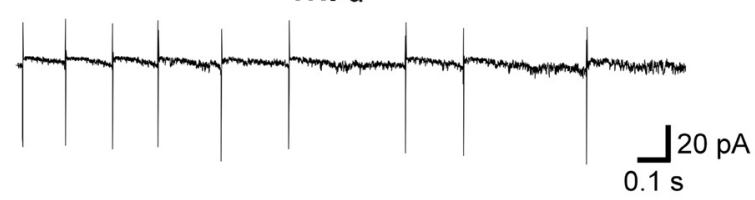

B

a

Control
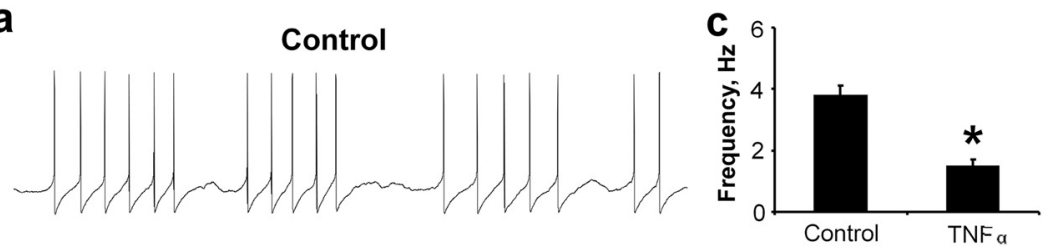

b

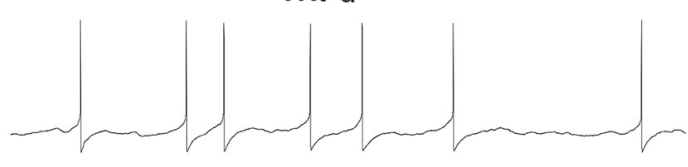

a

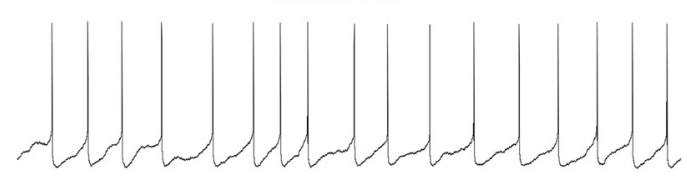

b

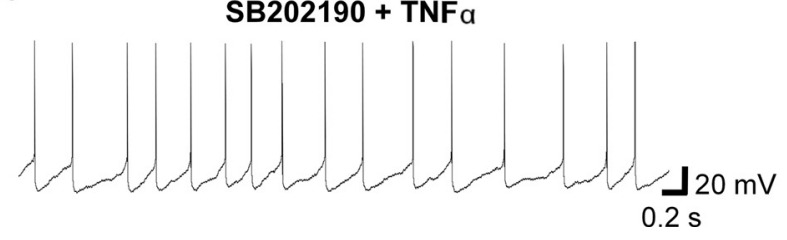

Figure 9. TNF $\alpha$ decreases the frequency of spontaneously active GABAergic neurons in spinal cord dorsal horn. $A$, Recorded in cell-attach mode, a GAD67 ${ }^{+}$spinal dorsal horn neuron showed spontaneous discharges when bicuculline, strychnine, DNQX, and D-AP-5 were added in the bath ( $\boldsymbol{a}$ ). Application of TNF $\alpha$ reduced the frequency of spontaneous discharges $(\boldsymbol{b})$; $\boldsymbol{c}$, averaged data showed decreased frequency of spontaneous discharges of GABAergic neurons after the application of TNF $\alpha(n=3)$. B, Whole-cell patch-clamp recordings from $\mathrm{GAD} 67^{+}$spinal dorsal horn neurons. $\boldsymbol{a}$, A representative recording from $\mathrm{GAD} 67^{+}$neurons showed spontaneous discharges. $\boldsymbol{b}$, After the application of TNF $\alpha$, the frequency of spontaneous discharges was reduced. c, Averaged data showed TNF $\alpha$ significantly reduced the frequency of spontaneous discharges of GABAergic neurons $(n=6)$. Bicuculline, strychnine, DNQX, and D-AP-5 were added in the bath. C, Intracellular blockade of $\mathrm{p} 38$ prevented the TNF $\alpha$-induced inhibition of spontaneous discharges of GABAergic neurons. $\boldsymbol{a}$, A representative recording from a GAD67 ${ }^{+}$spinal dorsal horn neuron showing spontaneous discharges with SB202190 (20 $\mu \mathrm{M}$ ) added in the pipette solution. $\boldsymbol{b}$, Additional application of TNF $\alpha$ had no effect on the spontaneous discharges of the recorded neuron. $c$, Averaged data showed the frequency of spontaneous discharges before and after the application of TNF $\alpha(n=4) .{ }^{*} p<0.01$ compared with baseline before application of TNF $\alpha$ (Student's paired $t$ test).

Chattopadhyaya B, Di Cristo G, Higashiyama H, Knott GW, Kuhlman SJ, Welker E, Huang ZJ (2004) Experience and activity-dependent maturation of perisomatic GABAergic innervation in primary visual cortex during a postnatal critical period. J Neurosci 24:9598-9611.

Choi JI, Svensson CI, Koehrn FJ, Bhuskute A, Sorkin LS (2010) Peripheral inflammation induces tumor necrosis factor dependent AMPA receptor 
A

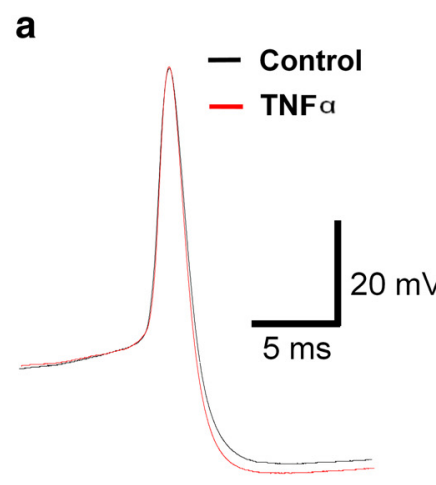

B

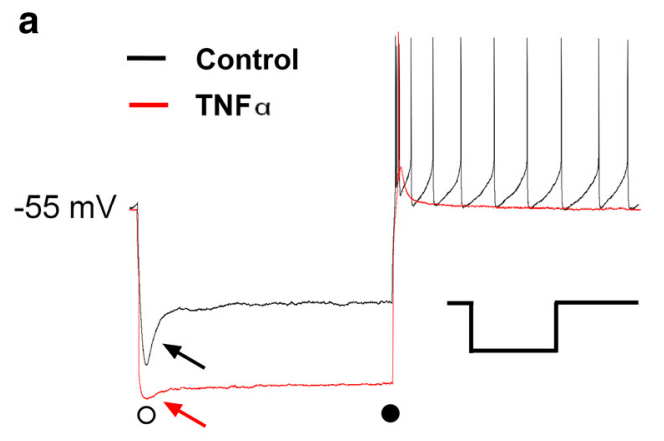

C
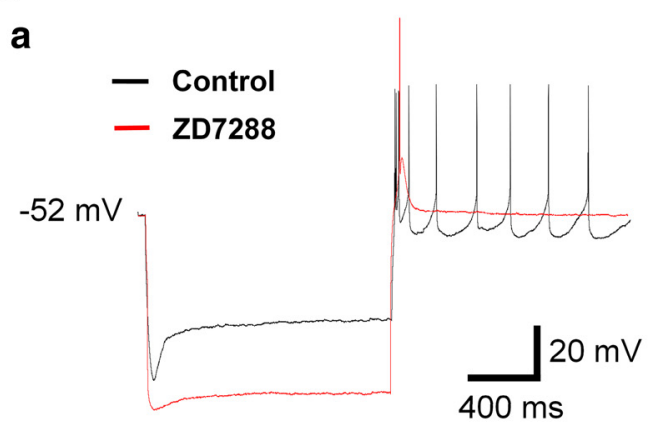

\section{b}

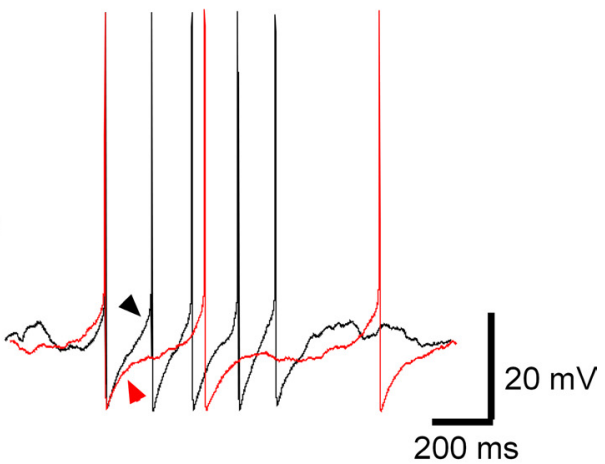

b

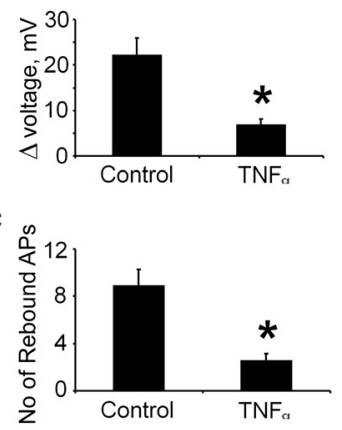

b

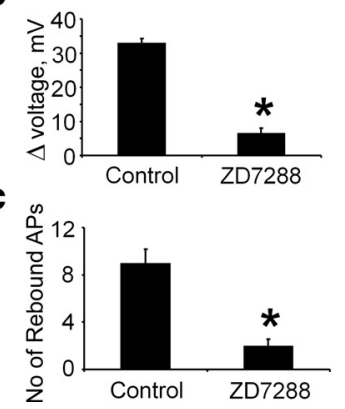

Figure 10. TNF $\alpha$ inhibits the hyperpolarization-activated cation currents $\left(I_{\mathrm{h}}\right)$ of GABAergic neurons of spinal dorsal horn. Aa , Action potentials of a $\mathrm{GAD} 67^{+}$neuron recorded in control solution (black) and after the application of TNF $\alpha$ (red) were superimposed to show no modification of action potential waveforms. $\boldsymbol{A} \boldsymbol{b}$, The depolarization ramp leading to action potential threshold was prolonged after the application of TNF $\alpha$ (red arrowhead) compared with control solution (black arrowhead), which led to a lower frequency of spontaneous discharges. $\boldsymbol{B} \boldsymbol{a}$, In current-clamp recordings, a hyperpolarizing current step (inset) induced a sag (black arrow) and rebound action potentials from $\mathrm{GAD67}^{+}$neurons (black line). Application of TNF $\alpha$ reduced both sag (red arrow) and the number of rebound action potentials in the same cell (red line). $\boldsymbol{B} \boldsymbol{b}, \boldsymbol{B} \boldsymbol{C}$, Averaged data of the changes in sag and the number of rebound action potentials after the application of $\operatorname{TNF} \alpha(n=9)$, respectively. The amplitude of sag was measured by subtracting the voltage induced at the end of the hyperpolarizing step $(\bullet)$ from the voltage induced at the initial of the hyperpolarizing step (O). C, ZD7288, a specific/h blocker, had similar effect with $\operatorname{TNF} \alpha(n=4) .{ }^{*} p<0.01$ compared with baseline before application of TNF $\alpha$ (Student's paired $t$ test).

trafficking and Akt phosphorylation in spinal cord in addition to pain behavior. Pain 149:243-253.

Cunha FQ, Poole S, Lorenzetti BB, Ferreira SH (1992) The pivotal role of tumor-necrosis-factor-Alpha in the development of inflammatory hyperalgesia. Br J Pharmacol 107:660-664.

Cunha TM, Verri WA Jr, Silva JS, Poole S, Cunha FQ, Ferreira SH (2005) A cascade of cytokines mediates mechanical inflammatory hypernociception in mice. Proc Natl Acad Sci U S A 102:1755-1760.

Czeschik JC, Hagenacker T, Schäfers M, Büsselberg D (2008) TNF-alpha differ- entially modulates ion channels of nociceptive neurons. Neurosci Lett 434:293-298.

Eaton MJ, Plunkett JA, Karmally S, Martinez MA, Montanez K (1998) Changes in GAD- and GABA-immunoreactivity in the spinal dorsal horn after peripheral nerve injury and promotion of recovery by lumbar transplant of immortalized serotonergic precursors. J Chem Neuroanat 16:57-72.

Eaton MJ, Martinez MA, Karmally S (1999) A single intrathecal injection of GABA permanently reverses neuropathic pain after nerve injury. Brain Res 835:334-339.

Ferreira SH, Lorenzetti BB, Poole S (1993) Bradykinin initiates cytokine-mediated inflammatory hyperalgesia. Br J Pharmacol 110:1227-1231.

Fitzsimmons BL, Zattoni M, Svensson CI, Steinauer J, Hua XY, Yaksh TL (2010) Role of spinal p38 alpha and beta MAPK in inflammatory hyperalgesia and spinal COX-2 expression. Neuroreport 21:313-317.

Gao YJ, Zhang L, Samad OA, Suter MR, Yasuhiko $\mathrm{K}$, Xu ZZ, Park JY, Lind AL, Ma Q, Ji RR (2009) JNK-induced MCP-1 production in spinal cord astrocytes contributes to central sensitization and neuropathic pain. J Neurosci 29:4096-4108.

Garry EM, Delaney A, Blackburn-Munro G, Dickinson T, Moss A, Nakalembe I, Robertson DC, Rosie R, Robberecht P, Mitchell R, Fleetwood-Walker SM (2005) Activation of p38 and p42/44 MAP kinase in neuropathic pain: Involvement of VPAC(2) and NK2 receptors and mediation by spinal glia. Mol Cell Neurosci 30:523-537.

Gasparini S, DiFrancesco D (1997) Action of the hyperpolarization-activated current (I-h) blocker ZD 7288 in hippocampal CA1 neurons. Pflugers Arch 435:99-106.

Grudt TJ, Perl ER (2002) Correlations between neuronal morphology and electrophysiologi$\mathrm{cal}$ features in the rodent superficial dorsal horn. J Physiol 540:189-207.

Hamill OP, Marty A, Neher E, Sakmann B, Sigworth FJ (1981) Improved patch-clamp techniques for high-resolution current recording from cells and cell-free membrane patches. Pflugers Arch 391:85-100.

Hantman AW, van den Pol AN, Perl ER (2004) Morphological and physiological features of a set of spinal substantia gelatinosa neurons defined by green fluorescent protein expression. J Neurosci 24:836-842.

Harris NC (1992) Sensitivity of transient outward rectification to ion channel blocking-agents in guinea-pig substantia-nigra pars compacta neurons in vitro. Brain Res 596:325-329.

Harris NC, Webb C, Greenfield SA (1989) A possible pacemaker mechanism in pars compacta neurons of the guinea-pig substantia nigra revealed by various ion channel blocking-agents. Neuroscience 31:355-362.

Heinke B, Ruscheweyh R, Forsthuber L, Wunderbaldinger G, Sandkühler J (2004) Physiological, neurochemical and morphological properties of a subgroup of GABAergic spinal lamina II neurones identified by expression of green fluorescent protein in mice. J Physiol 560:249-266.

Higuchi M, Aggarwal BB (1992) Modulation of 2 forms of tumornecrosis-factor receptors and their cellular-response by soluble receptors and their monoclonal-antibodies. J Biol Chem 267:2089220899.

Holmes GM, Hebert SL, Rogers RC, Hermann GE (2004) Immunocyto- 
chemical localization of TNF type 1 and type 2 receptors in the rat spinal cord. Brain Res 1025:210-219.

Ibuki T, Hama AT, Wang XT, Pappas GD, Sagen J (1997) Loss of GABAimmunoreactivity in the spinal dorsal horn of rats with peripheral nerve injury and promotion of recovery by adrenal medullary grafts. Neuroscience 76:845-858.

Ji RR, Samad TA, Jin SX, Schmoll R, Woolf CJ (2002) p38 MAPK activation by NGF in primary sensory neurons after inflammation increases TRPV1 levels and maintains heat hyperalgesia. Neuron 36:57-68.

Ji RR, Gereau RW 4th, Malcangio M, Strichartz GR (2009) MAP kinase and pain. Brain Res Rev 60:135-148.

Jin SX, Zhuang ZY, Woolf CJ, Ji RR (2003) p38 mitogen-activated protein kinase is activated after a spinal nerve ligation in spinal cord microglia and dorsal root ganglion neurons and contributes to the generation of neuropathic pain. J Neurosci 23:4017-4022.

Jin X, Gereau RW 4th (2006) Acute p38-mediated modulation of tetrodotoxin-resistant sodium channels in mouse sensory neurons by tumor necrosis factor- $\alpha$. J Neurosci 26:246-255.

Junger H, Sorkin LS (2000) Nociceptive and inflammatory effects of subcutaneous TNFalpha. Pain 85:145-151.

Kawasaki Y, Zhang L, Cheng JK, Ji RR (2008) Cytokine mechanisms of central sensitization: distinct and overlapping role of interleukin- $1 \beta$, interleukin-6, and tumor necrosis factor- $\alpha$ in regulating synaptic and neuronal activity in the superficial spinal cord. J Neurosci 28:5189-5194.

Khan AA, Diogenes A, Jeske NA, Henry MA, Akopian A, Hargreaves KM (2008) Tumor necrosis factor alpha enhances the sensitivity of rat trigeminal neurons to capsaicin. Neuroscience 155:503-509.

Lee JC, Laydon JT, McDonnell PC, Gallagher TF, Kumar S, Green D, McNulty D, Blumenthal MJ, Heys JR, Landvatter SW, Strickler JE, Mclaughlin MM, Siemens IR, Fisher SM, Livi GP, White JR, Adams JL, Young PR (1994) A protein-kinase involved in the regulation of inflammatory cytokine biosynthesis. Nature 372:739-746.

Lindenlaub T, Teuteberg P, Hartung T, Sommer C (2000) Effects of neutralizing antibodies to TNF-alpha on pain-related behavior and nerve regeneration in mice with chronic constriction injury. Brain Res 866:15-22.

Liu B, Li H, Brull SJ, Zhang JM (2002) Increased sensitivity of sensory neurons to tumor necrosis factor $\alpha$ in rats with chronic compression of the lumbar ganglia. J Neurophysiol 88:1393-1399.

Lüthi A, McCormick DA (1998) H-current: properties of a neuronal and network pacemaker. Neuron 21:9-12.

Maccaferri G, McBain CJ (1996) The hyperpolarization-activated current (I-h) and its contribution to pacemaker activity in rat CA1 hippocampal stratum oriens-alveus interneurones. J Physiol 497:119-130.

McCormick DA, Pape HC (1990) Properties of a hyperpolarizationactivated cation current and its role in rhythmic oscillation in thalamic relay neurons. J Physiol 431:291-318.

Moore KA, Kohno T, Karchewski LA, Scholz J, Baba H, Woolf CJ (2002) Partial peripheral nerve injury promotes a selective loss of GABAergic inhibition in the superficial dorsal horn of the spinal cord. J Neurosci 22:6724-6731.

Motagally MA, Lukewich MK, Chisholm SP, Neshat S, Lomax AE (2009) Tumour necrosis factor alpha activates nuclear factor kappa B signalling to reduce $\mathrm{N}$-type voltage-gated $\mathrm{Ca}^{2+}$ current in postganglionic sympathetic neurons. J Physiol 587:2623-2634.

Narita M, Shimamura M, Imai S, Kubota C, Yajima Y, Takagi T, Shiokawa M, Inoue T, Suzuki M, Suzuki T (2008) Role of interleukin-1 beta and tumor necrosis factor-alpha-dependent expression of cyclooxygenase-2 mRNA in thermal hyperalgesia induced by chronic inflammation in mice. Neuroscience 152:477-486.

Nicol GD, Lopshire JC, Pafford CM (1997) Tumor necrosis factor enhances the capsaicin sensitivity of rat sensory neurons. J Neurosci 17:975-982.

Ohtori S, Takahashi K, Moriya H, Myers RR (2004) TNF-alpha and TNFalpha receptor type 1 upregulation in glia and neurons after peripheral nerve injury: studies in murine DRG and spinal cord. Spine 29:1082-1088.

Oprée A, Kress M (2000) Involvement of the proinflammatory cytokines tumor necrosis factor- $\alpha$, IL- $1 \beta$, and IL- 6 but not IL- 8 in the development of heat hyperalgesia: effects on heat-evoked calcitonin gene-related peptide release from rat skin. J Neurosci 20:6289-6293.

Pape HC (1996) Queer current and pacemaker: the hyperpolarizationactivated cation current in neurons. Annu Rev Physiol 58:299-327.

Papp I, Szucs P, Holló K, Erdélyi F, Szabó G, Antal M (2006)
Hyperpolarization-activated and cyclic nucleotide-gated cation channel subunit 2 ion channels modulate synaptic transmission from nociceptive primary afferents containing substance $\mathrm{P}$ to secondary sensory neurons in laminae I-IIo of the rodent spinal dorsal horn. Eur J Neurosci 24:1341-1352.

Parada CA, Yeh JJ, Joseph EK, Levine JD (2003) Tumor necrosis factor receptor type-1 in sensory neurons contributes to induction of chronic enhancement of inflammatory hyperalgesia in rat. Eur J Neurosci 17:1847-1852.

Perkins MN, Kelly D (1994) Interleukin-1-beta induced Desarg(9)bradykininmediated thermal hyperalgesia in the rat. Neuropharmacology 33:657-660.

Pollock J, McFarlane SM, Connell MC, Zehavi U, Vandenabeele P, MacEwan DJ, Scott RH (2002) TNF- $\alpha$ receptors simultaneously activate $\mathrm{Ca}^{2+}$ mobilisation and stress kinases in cultured sensory neurones. Neuropharmacology 42:93-106.

Santoro B, Chen S, Luthi A, Pavlidis P, Shumyatsky GP, Tibbs GR, Siegelbaum SA (2000) Molecular and functional heterogeneity of hyperpolarization-activated pacemaker channels in the mouse CNS. J Neurosci 20:5264-5275.

Schäfers M, Lee DH, Brors D, Yaksh TL, Sorkin LS (2003a) Increased sensitivity of injured and adjacent uninjured rat primary sensory neurons to exogenous tumor necrosis factor-alpha after spinal nerve ligation. J Neurosci 23:3028-3038.

Schäfers M, Sorkin LS, Sommer C (2003b) Intramuscular injection of tumor necrosis factor-alpha induces muscle hyperalgesia in rats. Pain 104:579-588.

Schäfers M, Svensson CI, Sommer C, Sorkin LS (2003c) Tumor necrosis factor- $\alpha$ induces mechanical allodynia after spinal nerve ligation by activation of p38 MAPK in primary sensory neurons. J Neurosci 23: 2517-2521.

Shubayev VI, Myers RR (2001) Axonal transport of TNF-alpha in painful neuropathy: distribution of ligand tracer and TNF receptors. J Neuroimmunol 114:48-56.

Sivilotti L, Woolf CJ (1994) The contribution of GABAA and glycine receptors to central sensitization: disinhibition and touch-evoked allodynia in the spinal cord. J Neurophysiol 72:169-179.

Sommer C, Marziniak M, Myers RR (1998a) The effect of thalidomide treatment on vascular pathology and hyperalgesia caused by chronic constriction injury of rat nerve. Pain 74:83-91.

Sommer C, Schmidt C, George A (1998b) Hyperalgesia in experimental neuropathy is dependent on the TNF receptor 1. Exp Neurol 151:138-142.

Sommer C, Lindenlaub T, Teuteberg P, Schäfers M, Hartung T, Toyka KV (2001a) Anti-TNF-antibodies reduce pain-related behavior in two different mouse models of painful mononeuropathy. Brain Res 913:86-89.

Sommer C, Schäfers M, Marziniak M, Toyka KV (2001b) Etanercept reduces hyperalgesia in experimental painful neuropathy. J Peripher Nerv Syst 6:67-72.

Sorkin LS, Doom CM (2000) Epineurial application of TNF elicits an acute mechanical hyperalgesia in the awake rat. J Peripher Nerv Syst 5:96-100.

Sorkin L, Svensson CI, Jones-Cordero TL, Hefferan MP, Campana WM (2009) Spinal p38 mitogen-activated protein kinase mediates allodynia induced by first-degree burn in the rat. J Neurosci Res 87:948 -955.

Stellwagen D, Beattie EC, Seo JY, Malenka RC (2005) Differential regulation of AMPA receptor and GABA receptor trafficking by tumor necrosis factor- $\alpha$. J Neurosci 25:3219-3228.

Svensson CI, Marsala M, Westerlund A, Calcutt NA, Campana WM, Freshwater JD, Catalano R, Feng Y, Protter AA, Scott B, Yaksh TL (2003) Activation of p38 mitogen-activated protein kinase in spinal microglia is a critical link in inflammation-induced spinal pain processing. J Neurochem 86:1534-1544.

Svensson CI, Schäfers M, Jones TL, Powell H, Sorkin LS (2005) Spinal blockade of TNF blocks spinal nerve ligation-induced increases in spinal P-p38. Neurosci Lett 379:209-213.

Svensson CI, Medicherla S, Malkmus S, Jiang Y, Ma JY, Kerr I, BraininMattos J, Powell HC, Luo ZD, Chakravarty S, Dugar S, Higgins LS, Protter AA, Yaksh TL (2008) Role of p38 mitogen activated protein kinase in a model of osteosarcoma-induced pain. Pharmacol Biochem Behav 90: $664-675$.

Tartaglia LA, Goeddel DV (1992) 2 Tnf receptors. Immunol Today 13:151-153. 
Tartaglia LA, Weber RF, Figari IS, Reynolds C, Palladino MA Jr, Goeddel DV (1991) The 2 different receptors for tumor-necrosis-factor mediate distinct cellular-responses. Proc Natl Acad Sci U S A 88:9292-9296.

Tsuda M, Mizokoshi A, Shigemoto-Mogami Y, Koizumi S, Inoue K (2004) Activation of p38 mitogen-activated protein kinase in spinal hyperactive microglia contributes to pain hypersensitivity following peripheral nerve injury. Glia 45:89-95.

Vandenabeele P, Declercq W, Beyaert R, Fiers W (1995) Two tumour necrosis factor receptors: structure and function. Trends Cell Biol 5: 392-399.

Vince JE, Pantaki D, Feltham R, Mace PD, Cordier SM, Schmukle AC, Davidson AJ, Callus BA, Wong WW, Gentle IE, Carter H, Lee EF, Walczak H, Day CL, Vaux DL, Silke J (2009) TRAF2 must bind to cellular inhibitors of apoptosis for tumor necrosis factor (TNF) to efficiently activate NF-kappa B and to prevent TNF-induced apoptosis. J Biol Chem 284:35906-35915.

Wacnik PW, Eikmeier LJ, Simone DA, Wilcox GL, Beitz AJ (2005) Nociceptive characteristics of tumor necrosis factor-alpha in naive and tumorbearing mice. Neuroscience 132:479-491.

Watkins LR, Maier SF (2003) Glia: a novel drug discovery target for clinical pain. Nat Rev Drug Discov 2:973-985.

Watkins LR, Goehler LE, Relton J, Brewer MT, Maier SF (1995) Mechanisms of tumor necrosis factor- $\alpha$ (TNF- $\alpha$ ) hyperalgesia. Brain Res 692:244-250.
Willis WD, Coggeshall RE (2004) Sensory mechanisms of the spinal cord. New York: Plenum.

Woolf CJ, Allchorne A, Safieh-Garabedian B, Poole S (1997) Cytokines, nerve growth factor and inflammatory hyperalgesia: the contribution of tumor necrosis factor $\alpha$. Br J Pharmacol 121:417-424.

Yaksh TL (1989) Behavioral and autonomic correlates of the tactile evoked allodynia produced by a spinal glycine inhibition: effects of modulatory receptor systems and excitatory amino acid antagonists. Pain 37:111-123.

Yoshimura M, Jessell TM (1989) Membrane properties of rat substantia gelatinosa neurons in vitro. J Neurophysiol 62:109-118.

Zhang H, Xin W, Dougherty PM (2009) Synaptically evoked glutamate transporter currents in spinal dorsal horn astrocytes. Mol Pain 5:36.

Zhang JM, Li H, Liu B, Brull SJ (2002) Acute topical application of tumor necrosis factor $\alpha$ evokes protein kinase A-dependent responses in rat sensory neurons. J Neurophysiol 88:1387-1392.

Zhuang ZY, Wen YR, Zhang DR, Borsello T, Bonny C, Strichartz GR, Decosterd I, Ji RR (2006) A peptide c-Jun N-terminal kinase (JNK) inhibitor blocks mechanical allodynia after spinal nerve ligation: respective roles of JNK activation in primary sensory neurons and spinal astrocytes for neuropathic pain development and maintenance. J Neurosci 26: 3551-3560.

Zhuang ZY, Kawasaki Y, Tan PH, Wen YR, Huang J, Ji RR (2007) Role of the CX3CR1/p38 MAPK pathway in spinal microglia for the development of neuropathic pain following nerve injury-induced cleavage of fractalkine. Brain Behav Immun 21:642-651. 